\title{
The Creation of a Corridor Tour: A First Approach
}

\author{
Selene Viridiana Pérez Ramírez, Silvia Cartujano Escobar, Paula Ponce Lázaro, \\ Roque López Tarango, Crisóforo Álvarez Violante \\ Autonomous University of Morelos State, Morelos, Mexico
}

\begin{abstract}
Our country has an extraordinary tourist richness, proof of which is the southern region of the municipality of Tlaquiltenango, Morelos, which has a number of tourist attractions that could be exploited for the benefit of the community; however, these attractions are underused. In order to carry out a first approach to the object of study, a research with a qualitative approach was done, which allowed us to understand and deepen into the research topic from the perspective of the participants (inhabitants of the communities involved). The main objective of this paper is to investigate the perspective of the municipal authorities on the realization of an agreement on the participation in their communities, as well as to know from their point of view the economic, social, and cultural environment; Expand their experiences and the way they perceive their reality. The problem was approached from the design and the study with a sample oriented towards the qualitative research denominated homogenous sample. It was concluded that: The people interviewed feel a great love for their people and their roots. It was found that people have cultural identity and a great sense of belonging, and they consider that it is feasible to generate a tourist corridor since they do have the necessary attractions.
\end{abstract}

Keywords: rural tourism, ecotourism, regional development

\section{Introduction}

The main purpose of this research was to investigate the perspective of the municipal authorities (municipal assistants and public land commissaries) regarding the realization of a tourist corridor that involved their communities, as well as to know from their perspective the economic, social, and cultural environment; deepen their experiences and the way in which they perceive their reality. This paper is motivated by the main question as to whether it is feasible to generate a tourist corridor in the communities studied as the municipality of Tlaquiltenango has natural and cultural attractions.

Tlaquiltenango municipality is the one with the greatest territorial extension of the state of Morelos, which is located between the coordinates $18^{\circ} 37^{\prime} 44^{\prime \prime}$ north latitude of the Tropic of Cancer and between $90^{\circ} 09^{\prime}$ 37” west length of the Greenwich Meridian. Adjoin territorially in the north with the municipalities of Tlaltizapán, Ayala and Tepalcingo, in the south with the states of Guerrero and Puebla, in the west with Zacatepec, Jojutla and Puente de Ixtla, and in the east with the municipality of Tepalcingo (see Figure 1).

Selene Viridiana Pérez Ramírez, Research Professor, Higher Education School of Jojutla, Autonomous University of Morelos State. Email: selene@uaem.mx.

Silvia Cartujano Escobar, Research Professor, Higher Education School of Jojutla, Autonomous University of Morelos State.

Paula Ponce Lázaro, Research Professor, Higher Education School of Jojutla, Autonomous University of Morelos State.

Roque López Tarango, Research Professor, Higher Education School of Jojutla, Autonomous University of Morelos State.

Crisóforo Álvarez Violante, Research Professor, Higher Education School of Jojutla, Autonomous University of Morelos State. 


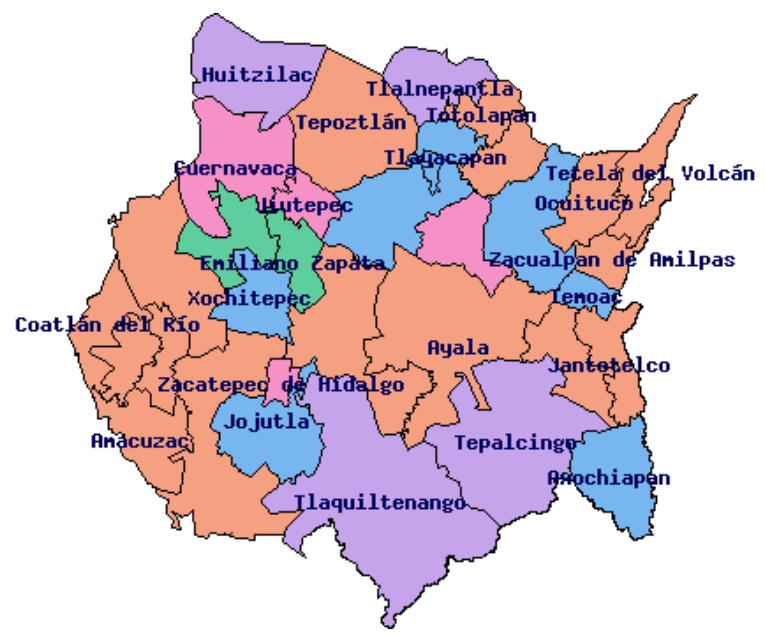

Figure 1. Map of the state of Morelos. Source: Internet.

It has a land area of 581,778 square kilometers and is located at an average altitude of 911 meters above sea level. According to the National Institute of Statistics and Geography (INEGI for its acronym in Spanish), until 2010, it had a population of 31,534 inhabitants (INEGI, 2010).

Among the main economic activities include agriculture, with $79 \%$ for rainfed agriculture and irrigation 21\%. Crops that are carried out are sugarcane, rice, onion, sorghum, tomatoes, corn, and beans. Besides, this activity is complemented by marketing their crops. It is noteworthy that they do not have the necessary infrastructure and support for improving the production and marketing to achieve that families from Tlaquiltenango obtain a benefit.

Another important activity is floriculture, derived from various nurseries of fruit trees, plants, and ornamental flowers that are produced in this area as well as livestock, which is developed by breeding of cattle, pigs, goats, sheep, and caballar. Poultry farming is also exploited as a way to stimulate the economy of the region, together with other secondary and tertiary sectors.

In the southern part of the municipality of Tlaquiltenango are the communities of La Mezquitera, Valle Vazquez and Chimalacatlán (objects of this study), which count with a variety of natural resources and archaeological sites, buildings of cultural and historical interest. Such attractions have remained underused, without reporting a real benefit to the general population; tourism is an activity that has not been developed effectively, although the fact of attracting people who want to know the areas of interest and attraction that are part of that site can be a trigger for the town's economy.

The above is a sample of the resources that can generate sustainable economic development, which translates into job creation in several branches or sectors, so it is important that people considered economically active recognize that they should have an entrepreneurial vision and that they commit to contribute to the economic development of not only their families, but also the municipality in general.

\section{Context of the Communities}

This project focuses on the generation of a tourist corridor that includes three communities in the southern part of the municipality of Tlaquiltenango, Morelos. The trajectory of this tourist corridor starts in the town of Jojutla, being the first destination the Mezquitera community, as second destination Valle Vazquez, to conclude in the village of Chimalacatlán (see Figure 2). 


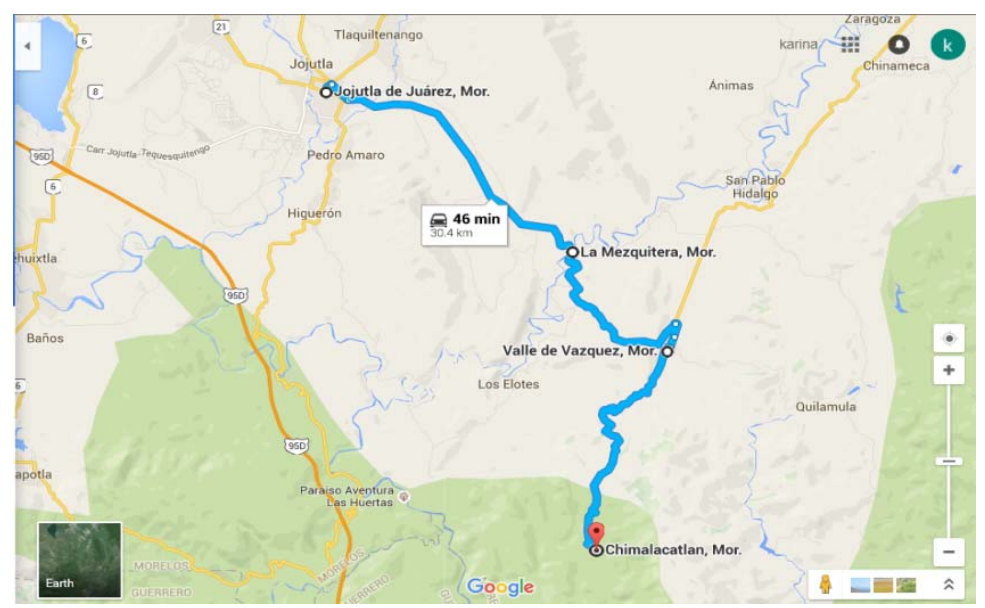

Figure 2. Location of the localities involved in the study. Source: Own.

The Mezquitera, or also known as the community the astillero, adjoins with the communities of: Santa Cruz, La Hera, and Las Bóvedas; it is at a medium height of 855 meters above sea level (Nuestro-mexico.com, s.f.), its climate is varied predominating the warm semi-dry climate, and presents temperatures ranging between $15^{\circ} \mathrm{C}$ and $35^{\circ} \mathrm{C}$.

The total population of this community is 536 people of which 259 are men and 277 are women, regarded as a rural community, since according to the National Institute of Statistics, Geography and Informatics (hereinafter INEGI by its acronym in Spanish), a population is considered rural when you have fewer than 2,500 inhabitants.

It should be noted that there are more adults than children in this population, since according to records, there are only 179 children aged 0-14 years. The aged over 15 amounted to a total of 357 people, of whom 35 people are elderly, i.e., who are older than 65 years old.

INEGI data show that the economically active population in this community is 142 people. Within this group are the people who regularly engaged in economic activities or are in a position to work, even if they are temporarily without work for reasons beyond their control. They are considered as members of the economically active people aged between 15 and 65 years old. However, housewives are not included, who do not receive remuneration.

In this community, there is a total of 190 homes, of which only 138 are inhabited, and the average number of occupants per each is 3.88 people.

The biggest tourist attraction of La Mezquitera is the former Hacienda San Jacinto Ixtoluca, located 13.8 $\mathrm{km}$ from the municipal seat, which is Tlaquiltenango (22 minutes), and $11.6 \mathrm{~km}$ of Jojutla (17 minutes), that is the population in which the tourist corridor would start. This was built in the 16th century, and it was used to receive and purify all the mineral extracted from the Sierra de Huautla. Currently, in the place only remains the walls and pillars that supported the huge building, as well as the aqueducts, from which amates protrude, trees whose stems and roots cling to the rock, offering a breathtaking scenery.

Currently, this building with an area of 35,000 sqm is guarded by an organization of 18 "ejidatarios" (holders of a share in common lands) who have taken care to preserve, care for and manage the place. Today, the former hacienda is used as a film set and for recording historical novels. 
The second tourist destination that makes up the corridor is the community of Valle de Vazquez, also known as Los Hornos; it is located at an altitude of 950 meters above sea level. Its population is 1,125 people, of which 546 are male and 579 are female.

The climate in this community is semi-dry to warm. Its flora and fauna is mainly composed of deciduous forest, of warm weather; jacaranda, flamboyant tree, cazahuate tree, ceiba tree and bougainvillea. Its fauna is made up by white-tailed deer, collared peccary, raccoon, badger, skunk, armadillo, hare common rabbit, coyote, bobcat, weasel, cacomixtle, opossum, bat, bird flag, chachalaca, magpie, vulture, crow, owl, songbirds, and ornamental birds.

The attractions of this community are: the former hacienda Valley Vazquez, a construction which is currently in commodate; occupied by the School of Bachelors ${ }^{1}$ of the State of Morelos (COBAEM by its acronym in Spanish); "Las Tazas", which are pools that are formed naturally during the rainy season; the Cierva stone, a large rock with engravings and the monastery of the nuns of Bethlehem.

The ultimate destination of the tourist corridor proposed in this research is the town of Chimalacatlán; which means "next to the Shields of reed grass". This name consists of "Chimalli": shield or protection, "Acatl”: reed grass and "Tlan": between or near, being the Chimalacate a plant known as "Gigantón" (which in Spanish means very big) and whose stems were used in the manufacture of shields (Aldama \& Díaz, 2013). According to INEGI (2010) (General census of population and housing by its acronym in Spanish), the population of Chimalacatlán is composed of 364 inhabitants, of which 185 are male and 179 are of the female gender.

In the community, there are two types of climate: one is semi-dry-semi-warm and the other is semi-dry-semi-warm; it does not have a well-defined winter and with the worst drought in the late fall, in the winter and in the early spring. Temperatures range between $15^{\circ} \mathrm{C}$ and $35^{\circ} \mathrm{C}$, precipitation is $909.8 \mathrm{~mm}$ of annual rainfall.

Despite being a very small population, it has a total of 91 households. Of these 91 homes, 14 are without floor, 84 have sanitary installations, 65 are connected to the public service, and 91 have access to electricity.

The flora consists mainly of jacarandas, flamboyant tree, cazahuate tree, ceiba tree, yellow amate, cuachalalate, chinchona, chiclillo (endemic plant), and cactus. And wildlife is constituted by the white-tailed deer, skunk, armadillo, hare, bird flag, magpie, rabbit, weasel, quail, iguanas, snakes, tlacuaches, badgers, roadrunners, and buzzards (Tevillo \& Alonso, 2004).

In this population, the practiced economic activities are agriculture and livestock.

The attractions of this town are the enchanted cave, located at the top of the mountain, which represents one of the most important findings within the State of Morelos and in which were found remains of animals that became extinct in the late Pleistocene age, about 10,000 years ago (Corona, 2005).

In the archaeological site are the pyramid and the ball game as well as the community museum showing the skeletal remains found in the enchanted cave, including the back of a skull belonging to an edentulous (paramylodon), extinct gender that bears some relation to the so-called anteaters and armadillos; plus there is a femur, a humerus, molars and various fragments of ribs and vertebrae of a bunodonte gomphothere, a group that is distantly related to mammoths and modern elephants (Corona, 2005).

Other attractions are the artisan workshops of lináloe ${ }^{2}$ essence and wild grape wine.

\footnotetext{
${ }^{1}$ In Mexico, the School of Bachelors has the equivalent of a high school.

2 The lináloe tree produces oil which has healing properties.
} 


\section{Theoretical Framework}

Mexico is a country with great tourism potential that throughout history has been growing continuously improving its position somehow over other countries in terms of tourism. According to Valadez (2015), in 1950, Mexico was No. 13 of the most visited countries in the world; according to the World Tourism Organization, until 2003, Mexico was No. 8 and now thanks to the strength of the infrastructure of tourist destinations, Mexico ranks first in Latin America.

There are several definitions of tourism, one of the first is referred by Gurria (1991, p. 14):

Tourism is a social phenomenon which is voluntary or temporary displacement of individuals or groups of individuals who move from their usual place to another, primarily because of recreation, leisure, culture or health, and who do not exercise any gainful activity nor remunerated, generating multiple interrelationships of social, economic and cultural importance.

Medlik and Burkart (1981) defined tourism as short and temporary movement of people to destinations outside the place of residence and work, and the activities included during the stay in those destinations. Tourism is the set of travel aimed at pleasure or preferential or commercial reasons and during which the absence of habitual residence is temporary (Boardman, 1973).

There are various types of tourism which are classified according to the temporal component or the purpose of the trip. Some types of tourism are: business, family or friends tourism, academic tourism, conventions and congresses, rest or leisure tourism, shopping tourism, health tourism or medical, religious tourism, sports tourism, cultural tourism, etc. (Sancho \& Buhalis, 1998). Besides the above, there are other types of tourism such as cultural tourism, hunting tourism, agritourism (Ibáñez \& Rodríguez, 2012), adventure tourism (Troncoso, 1999), etc..

Once the concept of tourism and their classification is known, it is important to know the concept of tourism development, which is the evolution of tourism due to the creation of strategies, policies, and programs to improve basic services and infrastructure programs, for ensuring the welfare and protecting the physical safety of tourists.

The development of a place should not be measured by tourist influx of visitors but by the wealth generated by tourism activity, i.e., the optimal number of visitors according to environmental resources of the area, the ability of local people to organize and guide tourism development, and the definition of products and services that meet the qualifications of the needs of the local population, which has to be the ultimate beneficiary of the tourism process, considering also the interests of future generations (Viñals, 2002).

On the other hand, tourism development in Mexico advanced in the 20s, when the country focused its efforts on creating a social climate that would allow the increase of tourist flows, focusing on tourism that is directed towards foreign tourists (Varisco, 2008).

In addition, Varisco (2008) mentioned that from a critical perspective, the causal relationship between tourism development and national or regional development is questioned from the 70s, with the first investigations in the countries considered underdeveloped. At the national level, tourism research restarts in the 80s, with the primary focus of tourism planification, maintaining the goal of developing activities to achieve regional development. 
Tourism development is an activity of great importance because from this derives the economic livelihood of many families around the world, given that $80 \%$ of those living on less than a dollar a day live in 12 countries of which in 11 tourism is their main source of wealth (Sancho \& Buhalis, 1998).

The importance of tourism in different nations for support of society is very significant; hence, it is important proper tourism development.

The notion of tourism and development must therefore be understood within the overall context, convinced that tourism can lead to less advanced countries to increase their participation in the global economy.

In conclusion, tourism development are all those improvements at the national and international levels that countries implement to improve the conditions of the tourist attractions as well as the customer care and tourism policies, among other aspects related to the subject; besides, as could be seen, implementing such development is essential because of the importance of this activity to the sustenance of the economy of nations.

\section{Method}

In order to have a first approach, a research with a qualitative approach was carried out to understand and deepen the study object by exploring it from the perspective of participants in a natural environment and in relation to the context; seeking to understand the perspective of the participants (individuals or small groups of people) about the phenomena that surround them, deepen their experiences, opinions and meanings, i.e., how participants perceive their reality subjectively (Hernández, Fernández, \& Baptista, 2010).

The way in which the problem was addressed was through an ethnographic design that allowed us to study the inhabitants of the three communities involved, since the ethnographic designs describe and analyze the beliefs, meanings, knowledge, ideas and practices of groups, cultures and communities (Álvarez-Gayou, 2003).

The population analyzed in this investigation was the inhabitants of the communities of the Mezquitera, Vazquez Valley, and Chimalacatán.

A sample oriented towards qualitative research called homogeneous sample was used since the selected units had a similar profile, i.e., in-depth interviews were made to municipal assistants and ejido commissioners of the three communities addressed in the study.

A guide for an open and unstructured interview was prepared, in which the questions were linked with the aim of investigating what was the perspective of municipal authorities regarding the realization of a tourist corridor in their community and if they thought that this project would benefit their communities. The tools used to record information were notes in notebooks, video recording, and photographs.

\section{Perspective of the Authorities of the Communities About the Project}

In this section, a report developed through the eyes, ideas, and perspectives of the municipal authorities of each of the three communities involved in the study is presented.

The main purpose was to investigate the perspective of local authorities (municipal assistants and ejido commissioners) with respect to the realization of a tourist corridor involving their communities, and to know from their point of view, the economic, social, and cultural environment; deepen their experiences and how they perceive their reality.

The content of the report is divided into three dimensions: environmental and infrastructure, economic and socio-cultural. 


\section{Environmental and Infrastructure Dimension}

Regarding this aspect, all respondents felt that their communities are beautiful places and that can be very attractive to both domestic and foreign tourists; however, there is not "a proper" project, aiming to exploit its natural resources. They believe it is necessary a good infrastructure in roads and motorways that allow access to their communities. This would facilitate the arrival of tourists.

In the case of La Mezquitera, the former hacienda San Jacinto Ixtoluca does not have water service and it has to be pumped from the river, so it is difficult to give a good service to people who come to know the site: "We cannot help them as we wish, we lack even the basics, like water". However, despite the lack of infrastructure, all respondents agreed that within their communities the generation of a tourist corridor is feasible, as it has the attractions needed to do so.

\section{Economic Dimension}

The residents of communities have tried to organize, without any financial support or advice from the government to promote its tourist attractions. They stated that there has been isolate support from federal programs, but people soon after having received such financial support do not reinvest it, this is partly because there is no government monitoring and the training for projects to flourish.

Currently, there is no financial support from government agencies for the dissemination of the tourist attractions of the community. Temporary jobs have been implemented (the construction of two rooms in the former hacienda San Jacinto, digging in the haunted cave Chimalacatlán), which have lasted an average of two months; however, despite the short duration, respondents consider that during that period there was work, home economics was benefited, the respondents even said that "there was a change in the way we live". They consider that the generation of a tourist corridor within their communities would economically benefit the people and would help to "maintain our families".

\section{Socio-cultural Dimension}

In the three communities studied are held traditional village festivals, these are organized by the municipal assistants and with the collaboration of primary, secondary, or high schools (School of Bachelors), as applicable. They considered it important to continue performing these festivals since it is "remembering our roots and passing on the legacy of our ancestors". They stated that "the love of our people makes us want to continue with the traditions" and that "the festivals that take place in our community can be interesting for foreign tourists”.

\section{Conclusions}

During in-depth interviews and through observation, we realized that:

(1) Those interviewed have a great love for their village, their people, and their roots. It was found in them cultural identity and a sense of belonging;

(2) It is perceived a feeling of abandonment by the government, because they do not have the necessary support both economic as well as training for letting people know about their tourist attractions and that they can be visited by both domestic and foreign tourists, thus generating an economical profit for the families living in these communities. They are eager for new opportunities that will enable them to meet their basic needs and to grow personally and collectively; 
(3) They believe that the generation of a tourist corridor since they have attractions (natural and cultural) needed is feasible. They are clear that by creating the corridor, jobs would be created that would help their badly affected economically community, therefore their quality of life would improve;

(4) They express the willingness to organize themselves for the benefit of the community, through a project like this, enabling them to enhance tourism in the region, which could be a real driver of development and social welfare.

\section{References}

Aldama, R., \& Díaz, J. (2013). Collection and assembly of insects in Chimalacatlán, Morelos. Hypatia Digital Magazine. Retrieved from http://revistahypatia.org/59-excursiones/colecta-y-montaje.html

Álvarez-Gayou, J. (2003). How to do qualitative research: Fundamentals and methodology. Mexico: Paidós.

Boardman, R. (1973). Management and cost analysis in hotels and restaurants (3rd ed.). (Trans. L. Muñoz). Madrid: Ibérico Europeo de Ediciones, S.A.

Corona, M. E. (2005). Cultural supplement the tlacuache. INAH Morelos.

Gurria, M. (1991). Introduction to tourism. Mexico: Trillas.

Hernández,, S. R., Fernández, C. C., \& Baptista, L. P. (2010). Investigation methodology. Mexico: Editorial McGraw-Hill.

Ibáñez, R., \& Rodríguez, I. (2012). Types and history of tourism: Traditional tourism and alternative tourism.

INEGI. (2010). Retrieved from http://www.inegi.org.mx/

Medlik, S., \& Burkart, A. J. (1981). Turismo: Pasado, presente y futuro. Heinemann. Londres.

Sancho, A., \& Buhalis, D. (1998). Introduction to tourism. Madrid: World Tourism Organization.

Tevillo, B. Z., \& Alonso, P. H. (2004). Prodigies of nature. Haunted Cave Chimalacatlán. Retrieved from http://basica.primariatic.sep.gob.mx/descargas/colecciones/proyectos/red_escolar/publi_prodigios/chimalacatlan/chimalacatl an.htm

Troncoso, B. (1999). Sustainable tourism and ecotourism. Paper presented at the Ninth National Students Convention of Hotel and Tourism, Margarita Island, Venezuela. Retrieved from http://kiskeya-alternative.org/publica/bolivar/ecoturis.htm

Valadez, R. (2015). Journalism needs investment. México: Milenio.

Varisco, C. (2008). Tourism development and local development: Competitiveness of tourist destinations of sun and beach (Doctoral dissertation, National University of Mar del Plata).

Viñals, M. (2002). Tourism in natural and rural areas. Polytechnic University of Valencia. 